\title{
Mechanism of the oxidation of nitric oxide with oxygen
}

\author{
Józef Głowiński ${ }^{1}$, Józef Hoffmann ${ }^{1}$, Marcin Wilk ${ }^{2 *}$ \\ ${ }^{1}$ Wroclaw University of Science and Technology, Wybrzeże Wyspiańskiego 27, 50-370 Wroclaw, Poland \\ ${ }^{2}$ Eukasiewicz Research Network - New Chemical Syntheses Institute, al. Tysiaclecia Państwa Polskiego 13a, 24-110 \\ Pulawy, Poland \\ "Corresponding author: e-mail: marcin.wilk@ins.lukasiewicz.gov.pl
}

\begin{abstract}
Very fast reactions of forming higher nitrogen oxides set out an equilibrium framework for the course of the reaction of nitrogen monoxide oxidation. The slow course of reaction of nitrogen monoxide with oxygen permanently violates the created equilibria. In particular, the equilibrium of the oxidation reaction of nitrogen monoxide with nitrogen dioxide. The contribution of this reaction to the transformation of nitrogen monoxide in the conditions of nitrogen trioxide removal from the gas phase was estimated.
\end{abstract}

Keywords: nitrogen monoxide, oxygen, mechanism, kinetic, equilibrium, nitrogen trioxide.

\section{INTRODUCTION}

The reaction of nitrogen monoxide oxidation:

$2 \mathrm{NO}+\mathrm{O}_{2} \stackrel{k_{0}}{\longrightarrow} 2 \mathrm{NO}_{2}$

has been known and utilized for over 100 years, and it is always realized with the simultaneous absorption of oxidation products. It is considered as a complex reaction, although its intermediate stage is not clearly identified. From the kinetic point of view, it is an irreversible, third-order reaction with the atypical temperature dependence of the effective reaction rate coefficient $k_{0}$, as has been frequently confirmed ${ }^{1,3}$.

The discussed reaction ( $\mathrm{r} 0$ ) is always accompanied by the reactions leading to the formation of higher nitrogen oxides:

$\mathrm{NO}+\mathrm{NO}_{2} \underset{{ }_{-1}}{\stackrel{{ }_{1}}{\longrightarrow}} N_{2} \mathrm{O}_{3}$

$2 \mathrm{NO}_{2} \underset{k_{-2}}{\stackrel{k_{2}}{\rightleftarrows}} \mathrm{N}_{2} \mathrm{O}_{4}$

$\mathrm{NO}_{2}+\mathrm{NO}_{3} \underset{k_{-3}}{\stackrel{k_{3}}{\longrightarrow}} \mathrm{N}_{2} \mathrm{O}_{5}$

$\mathrm{NO}+\mathrm{NO}_{3} \underset{{ }_{-4}}{\stackrel{k_{4}}{\longrightarrow}} \mathrm{NO}_{2}+\mathrm{NO}_{2}$

The rates of both component reactions (r1) and (r2) are much higher than the rate of NO oxidation reaction. During the reaction $(\mathrm{r} 0)$ they reach the equilibrium state. In turn, reactions ( $\mathrm{r} 3)$ and $(\mathrm{r} 4)$ contribute to a lesser extent to the nitrogen monoxide transformation, due to very low concentrations of $\mathrm{N}_{2} \mathrm{O}_{5}$ and $\mathrm{NO}_{3}$ oxides.

In practice, the oxidation of nitrogen monoxide is considered taking into account either the reaction (r0) itself or - as e.g. in absorption processes - the reaction $(\mathrm{r} 0)$ in combination with the equilibrium of reactions (r1) and $(\mathrm{r} 2)^{4}$. In this work, it was decided to subject the five reactions indicated above to the kinetic analysis.

The following set of kinetic equations was considered:

$$
\begin{array}{ll}
\frac{d c_{N O}}{d t}=-2 r_{0}-r_{1}-r_{4} & c_{N O}(0)=c_{N O, 0} \\
\frac{d c_{N O_{2}}}{d t}=2 r_{0}-r_{1}-2 r_{2}-r_{3}+2 r_{4} & c_{N_{2}}(0)=0 \\
\frac{d c_{O_{2}}}{d t}=-r_{0} & c_{O_{2}}(0)=c_{O_{2}, 0} \\
\frac{d c_{N O_{3}}}{d t}=-r_{3}-r_{4} & c_{N O_{3}}(0)=0 \\
\frac{d c_{N_{2} O_{3}}}{d t}=r_{1} & c_{N_{2} O_{3}}(0)=0 \\
\frac{d c_{N_{2} O_{4}}}{d t}=r_{2} & c_{N_{2} O_{4}}(0)=0 \\
\frac{d c_{N_{2} O_{5}}}{d t}=r_{3} & c_{N_{2} O_{5}}(0)=0
\end{array}
$$

The rates of reactions ( $\mathrm{r} 0)$ and $(\mathrm{r} 1)-(\mathrm{r} 4)$ are as follows:

$$
\begin{aligned}
& r_{0}=k_{0} c_{\mathrm{NO}}^{2} c_{\mathrm{O}_{2}} \\
& r_{1}=k_{1} c_{\mathrm{NO}_{\mathrm{O}} \mathrm{NO}_{2}}-k_{-1} c_{\mathrm{N}_{2} \mathrm{O}_{3}} \\
& r_{2}=k_{2} c_{\mathrm{NO}_{2}} c_{\mathrm{NO}_{2}}-k_{-2} c_{\mathrm{N}_{2} \mathrm{O}_{4}} \\
& r_{3}=k_{3} c_{\mathrm{NO}_{2}} c_{\mathrm{NO}_{3}}-k_{-3} c_{\mathrm{N}_{2} \mathrm{O}_{5}} \\
& r_{4}=k_{4} c_{\mathrm{NO}} c_{\mathrm{NO}_{3}}-k_{-4} c_{\mathrm{NO}_{2}}^{2}
\end{aligned}
$$

The rate constants of reactions (r0)-(r4) are taken from the NIST Chemical Kinetics Database ${ }^{5}$. The values are in units of $\mathrm{mol} / \mathrm{dm}^{3} / \mathrm{s}$ :

$\mathrm{k}_{0}=1.197 \times 10^{3} \exp (530 / \mathrm{T})$

$\mathrm{k}_{1}=4.71 \times 10^{9}(\mathrm{~T} / 298)^{1,40}$

$\mathrm{k}_{-1}=4.70 \times 10^{15}(\mathrm{~T} / 298)^{0,40} \exp (-4880 / \mathrm{T})$

$\mathrm{k}_{2}=6.02 \times 10^{8}$

$\mathrm{k}_{-2}=1,15 \times 10^{16} \exp (-6460 / \mathrm{T})$

$\mathrm{k}_{3}=1.14 \times 10^{9}(\mathrm{~T} / 298)^{0,20}$

$\mathrm{k}_{-3}=9.71 \times 10^{14}(\mathrm{~T} / 298)^{0,10} \exp (-11120 / \mathrm{T})$

$\mathrm{k}_{4}=1.08 \times 10^{10} \exp (110 / \mathrm{T})$

$\mathrm{k}_{-4}=6.17 \times 10^{8}(\mathrm{~T} / 298)^{0,73} \exp (-10550 / \mathrm{T})$

The set of differential equations was solved using the Stiff procedure ${ }^{6}$. The presented results refer to the following conditions: pressure of $1 \mathrm{~atm}$, temperature of $273 \mathrm{~K}$, reaction time of $20 \mathrm{~s}$ and an initial mixture composition of $11.73 \% \mathrm{NO}$ and $6.39 \% \mathrm{O}_{2}$ (by volume). 
In the analyzed system, a slow reaction (r0) is accompanied by two fast reactions (r1) and (r2). Assuming the equilibrium of the reactions ( $\mathrm{r} 1)$ and ( $\mathrm{r} 2)$ allows determining $\mathrm{N}_{2} \mathrm{O}_{3}$ and $\mathrm{N}_{2} \mathrm{O}_{4}$ concentrations from the algebraic equations. From the perspective of the nitrogen monoxide transformation, the results from this approximate solution are similar to those obtained from the full kinetic model (1). Taking into account the reaction rates $r_{1}$ and $r_{2}$ different from zero makes it possible to track the dependency between changes in the concentration of nitrogen oxides and nitrogen monoxide. The reconnaissance calculations, involving reactions ( $(\mathrm{r} 0)-(\mathrm{r} 2)$, supplemented with an additional reaction of di-nitrogen oxides removal from the gas phase, showed inter alia, that the rate of nitrogen monoxide conversion is the sum of $2 r_{0}$ rates of the reaction of this nitrogen oxide with oxygen and some extra rate. The additional reaction rate can be linked to the components $r_{+1}$ and $r_{-1}$ of the rate of nitrogen monoxide oxidation with nitrogen dioxide ${ }^{7}$.

\section{SIMULATION RESULTS}

The concentrations of nitrogen dioxide and nitrogen tetra-oxide increase during the transformation of nitrogen monoxide, and the concentration of nitrogen trioxide also increases, although only up to a certain point. The concentration of nitrogen trioxide decreases during the subsequent stages of the reaction. This behaviour results in the transformation of nitrogen monoxide, mainly to nitrogen dioxide and its dimeric form. The ratios of the concentration of the reactions $(\mathrm{r} 1)$ and $(\mathrm{r} 2)$ products to the concentration of the substrates/reactants of the respective reactions remain virtually constant. Thus, the reaction of nitrogen monoxide with oxygen (r0) runs parallel to practically equilibrium reactions $(\mathrm{r} 1)$ and (r2). These results confirm the current understanding of how the reaction of nitrogen monoxide oxidation occurs.
System without removing the nitrogen trioxide from the gas phase

The results of a simulation performed without assuming the equilibrium of reactions (r1) and (r2) indicate a positive value of the rate of NO concentration change, with the simultaneous decrease of its concentration. Similarly, increasing the concentration of nitrogen trioxide in the initial period of $\mathrm{NO}$ transformation takes place at a negative value of the rate of $\mathrm{N}_{2} \mathrm{O}_{3}$ concentration change in the whole transformation range (Table 1). Both aforementioned behaviours, reflected in the set of equations (1), are atypical in chemical kinetics.

It is worth noting, that the current concentration of nitrogen monoxide $\mathrm{c}_{\mathrm{NO}}$ is practically the same as the concentration $\mathrm{c}_{\mathrm{NO}, \mathrm{e}}$, calculated from the assumed equilibrium of the reaction ( $\mathrm{r} 1)$. The simulated rate of $\mathrm{NO}$ concentration change is positive (except for the first calculation point), while for $\mathrm{N}_{2} \mathrm{O}_{3}$ oxide it is negative. The above results are inconsistent with the changes in the concentrations of both oxides.

The first atypical result is caused by introducing additional components in the expression describing the rate of NO concentration change. The rate of reaction $(\mathrm{r} 0)$, $r_{0}$, is low, and the net rate of reaction ( $\left.\mathrm{r} 1\right), r_{1}$, is much higher in absolute terms and is negative. This causes the rate of nitrogen monoxide concentration change to be formally positive and practically equal to $-r_{1}$. Explaining the increase in $\mathrm{N}_{2} \mathrm{O}_{3}$ concentration with the reaction rates, suggesting a loss of this oxide, is a difficult task, taking into account only the set of reactions used in the simulation.

Analysis of simulation results in terms of the concentrations obtained shows a very close bond between all the considered nitrogen oxides. The simulation results obtained from the set of differential equations (1) can be in fact reproduced from the set of algebraic equations, which consists of two equations expressing the equilibrium of the reaction (r1) and (r2) and the nitrogen balance equation. If the concentration of one of the

Table 1. Simulation results - an excerpt for 100 measurement points; $r_{N O}$ and $r_{N 2 O 3}$ denote the right sides of the respective kinetic equations (1) - these are rates obtained in the simulation; the actual rate $d c_{N O / d t}$ and $d c_{N 2 O 3 / d t}$ are calculated on the basis of nitrogen oxides concentration changes

\begin{tabular}{|c|c|c|c|c|c|c|c|}
\hline \multirow{2}{*}{$t$} & $c_{N O}$ & $c_{N O, e}$ & $r_{N O}$ & $\frac{d c_{N O}}{d t}$ & $c_{N_{2} O_{3}}$ & $r_{N_{2} O_{3}}$ & $\frac{d c_{N_{2} O_{3}}}{d t}$ \\
\hline \multirow{2}{*}{$\mathrm{s}$} & $\frac{m o l}{d m^{3}}$ & $\frac{m o l}{d m^{3}}$ & $\frac{m o l}{d m^{3} s}$ & $\frac{m o l}{d m^{3} s}$ & $\frac{m o l}{d m^{3}}$ & $\frac{m o l}{d m^{3} s}$ & $\frac{m o l}{d m^{3} s}$ \\
\hline 0 & 0.00524 & - & -0.00125 & -0.00125 & $1.00 \mathrm{E}-12$ & $-5.65 \mathrm{E}-05$ & 0.000119 \\
\hline 0.421 & 0.004700 & 0.004701 & 2.8379 & -0.00101 & $6.66 \mathrm{E}-05$ & -2.8389 & $8.36 \mathrm{E}-05$ \\
\hline 0.647 & 0.004480 & 0.004481 & 4.3009 & -0.00091 & $8.36 \mathrm{E}-05$ & -4.3017 & $6.80 \mathrm{E}-05$ \\
\hline & & & & & & & \\
\hline 2.815 & 0.003282 & 0.003282 & 1.9120 & -0.00035 & 0.000124 & -1.9124 & $5.66 \mathrm{E}-07$ \\
\hline 3.135 & 0.003175 & 0.003175 & 1.5051 & -0.00031 & 0.000124 & -1.5055 & $-1.85 \mathrm{E}-06$ \\
\hline 3.295 & 0.003125 & 0.003126 & 1.3510 & -0.00029 & 0.000125 & -1.3513 & $-2.68 \mathrm{E}-06$ \\
\hline & & & & & & & \\
\hline 8.735 & 0.002170 & 0.002171 & 0.1328 & -0.00011 & 0.000112 & -0.1329 & $-2.25 \mathrm{E}-06$ \\
\hline 8.895 & 0.002153 & 0.002153 & 0.1267 & -0.0001 & 0.000112 & -0.1268 & $-2.42 \mathrm{E}-06$ \\
\hline 9.055 & 0.002137 & 0.002137 & 0.12105 & -0.0001 & 0.000111 & -0.12115 & $-2.60 \mathrm{E}-06$ \\
\hline & & & & & & & \\
\hline 19.61 & 0.001500 & 0.001500 & 0.0149 & $-5.74 \mathrm{E}-05$ & $8.88 \mathrm{E}-05$ & -0.01498 & $3.91 \mathrm{E}-06$ \\
\hline 19.93 & 0.001489 & 0.001489 & 0.0143 & $-7.55 \mathrm{E}-05$ & $8.83 \mathrm{E}-05$ & -0.01427 & $8.91 \mathrm{E}-06$ \\
\hline 20 & 0.001487 & 0.001487 & -0.0092 & $-8.00 \mathrm{E}-05$ & $8.82 \mathrm{E}-05$ & -0.00918 & $1.01 \mathrm{E}-05$ \\
\hline
\end{tabular}


nitrogen oxides (nitrogen monoxide) is assumed, then from the above set of equations, the concentrations of 3 remaining nitrogen oxides are obtained. The results of such equilibrium calculations were compared with the simulation results and were collected in Table 2.

The rates of nitrogen monoxide concentration change, $d c_{N O} / d t$ were compared with the rate of nitrogen monoxide oxidation with oxygen, $2 r_{0}$. The ratio of these values is slightly higher or slightly lower than one. The average value of this ratio for 100 calculation points is 1.003 , so it is virtually equal to 1 . Thus, the transformation of nitrogen monoxide occurs only according to the reaction $(\mathrm{r} 0)^{7}$.

\section{System with removal of nitrogen trioxide from the gas phase}

The reaction behavior described above (r0)-(r4) under the conditions without removal of oxides from the gas phase was compared with the situation when the mentioned reactions run with simultaneous removal of nitrogen oxides from the gas phase. For the sake of clarity, it was assumed, that only the nitrogen trioxide, crucial for the transformation of nitrogen monoxide leaves the gaseous phase at a rate proportional to its current concentration:

$N_{2} O_{3(g)} \stackrel{k_{5}}{\longrightarrow} N_{2} O_{3(c)}$

The kinetic model (1) includes, in addition to the five reactions $(\mathrm{r} 0)-(\mathrm{r} 4)$, an additional reaction $(\mathrm{r} 5)$ in the gas phase.

Comparison of the rate of change in the concentration of nitric oxide with the reaction $(\mathrm{r} 0)$ rate leads in the analyzed system with the removal of nitrogen trioxide, to approximate equations:

$\frac{-d c_{N O} / d t}{2 r_{0}} \approx 2 \quad \frac{-d c_{O_{2}} / d t}{r_{0}} \approx 1$

This ratio of the rate of nitrogen monoxide concentration change turns out to be different from 1 . It depends on the rate at which nitrogen trioxide leaves the gas phase. The indicated value 2 in equation (4), as a mean value, of course, does not mean a two-fold increase in the rate. Nitrogen monoxide in reactions (r0) and (r1) is a common reagent. The consequence of its oxidation with nitrogen dioxide is the reduction of $\mathrm{r}_{0}$ rate, resulting from a decrease in NO concentration. This reduction is partially compensated by a slightly higher oxygen concentration.

The removal of nitrogen trioxide from the gas phase promotes an increase in the rate of nitrogen monoxide conversion. Along with the rate of nitrogen trioxide removal, the degree of oxygen conversion decreases. In addition to the conversion of nitrogen monoxide in the reaction with oxygen, the reaction with the nitrogen dioxide produced in reaction $\left(\mathrm{r}_{0}\right)$ proceeds. One can write an equation ${ }^{7}$ :

$-d c_{N O} / d t=2 r_{0}+\Delta r$

The rate $\Delta \mathrm{r}$ is equal to the difference between the rate $-\mathrm{dc}_{\mathrm{NO}} / \mathrm{dt}$ and the rate $2 \mathrm{r}_{0}$. In column 5 of Table 3 , the average values of this additional rate were collected.

The ratio $0.544 \beta / \alpha$ of reacted oxygen and nitrogen monoxide is in all cases lower than the stoichiometric value of 0.5 , also in the system without removal of nitrogen trioxide. In this case, the analyzed value shows a continuous increase from 0.438 to 0.488 . If $\mathrm{k}_{5}$ is equal to 0.1 and 0.5 , this value initially increases and then decreases. For a large value of $k_{5}$, a constant decrease in the analyzed ratio is observed.

It is obvious that the magnitude of $\Delta \mathrm{r}$ value is related to the reaction $(\mathrm{r} 1)$ of nitrogen monoxide oxidation with nitrogen dioxide. It turns out, that the rate $\Delta \mathrm{r}$ is described by the approximate equations $(6)^{7}$ :

$\Delta r \approx r_{1, e f} \approx k_{1, e f} c_{N O} c_{N O_{2}}$

$\Delta r \approx r_{-1, e f} \approx k_{-1, e f} c_{N_{2} O_{3}}$

The above formulas are of the same form as the components of the reaction rate $(\mathrm{r} 1)$, hence the determination of the analyzed rate $\Delta \mathrm{r}$ as $\mathrm{r}_{1, \mathrm{ef}}$ or $\mathrm{r}_{-1, \mathrm{ef}}$. Values

Table 2. Comparison of the concentration of nitrogen oxides on the third and fourth oxidation degrees. The initial concentration of nitrogen monoxide $5.24 \cdot 10^{-3} \mathrm{~mol} / \mathrm{dm}^{3}$; the assumed concentration of nitrogen monoxide represents $\alpha-$ conversion degree of NO

\begin{tabular}{|c|r|c|r|r|r|r|}
\hline Conversion degree of NO & \multicolumn{3}{|c|}{$\begin{array}{c}\text { Kinetic calculations } \\
\text { concentration } 10^{4} \mathrm{~mol} / \mathrm{dm}^{3}\end{array}$} & \multicolumn{3}{c|}{$\begin{array}{c}\text { Equilibrium calculations } \\
\text { concentration } 10^{4} \mathrm{~mol}^{3} / \mathrm{dm}^{3}\end{array}$} \\
\hline $\mathbf{\alpha}$ & $\mathbf{N O}_{\mathbf{2}}$ & $\mathbf{N}_{\mathbf{2}} \mathbf{O}_{3}$ & $\mathbf{N}_{\mathbf{2}} \mathbf{O}_{\mathbf{4}}$ & $\mathbf{N O}_{2}$ & $\mathbf{N}_{\mathbf{2}} \mathbf{O}_{3}$ & $\mathbf{N}_{\mathbf{2}} \mathbf{O}_{4}$ \\
\hline 0.333 & 6.562 & 1.216 & 4.250 & 6.556 & 1.215 & 4.244 \\
\hline 0.400 & 7.465 & 1.246 & 5.502 & 7.460 & 1.245 & 5.495 \\
\hline 0.502 & 8.755 & 1.213 & 7.568 & 8.750 & 1.212 & 7.560 \\
\hline 0.600 & 9.903 & 1.101 & 9.684 & 9.900 & $1.1-1$ & 9.676 \\
\hline 0.667 & 10.645 & 0.985 & 11.189 & 10.642 & 0.985 & 11.181 \\
\hline
\end{tabular}

Table 3. Conversion degree $\alpha$ of nitrogen monoxide and $\beta$ of oxygen, ratio of reacted oxygen and nitrogen monoxide (number 0.544 is the ratio of initial concentration of oxygen and nitric oxide), $\Delta \mathrm{r}$ rate of change of nitrogen monoxide concentration in the reaction (r1); time $20 \mathrm{~s}$, different rate of removal of nitrogen trioxide

\begin{tabular}{|c|c|c|c|c|c|}
\hline $\begin{array}{l}k_{5} \\
\mathrm{~s}^{-1}\end{array}$ & $\alpha$ & $\beta$ & $\begin{array}{c}0.544 \beta / \alpha \\
\text { range from - to }\end{array}$ & $\begin{array}{l}\Delta \mathrm{r} \cdot 10^{5} \\
\mathrm{~mol} / \mathrm{dm}^{3} / \mathrm{s}\end{array}$ & $\begin{array}{c}\mathrm{k}_{1, \mathrm{ef}} \\
\mathrm{dm}^{3} / \mathrm{mol} / \mathrm{s}\end{array}$ \\
\hline 0 & 0.716 & 0.642 & $0.438-0.488$ & 024 & - \\
\hline 0.1 & 0.737 & 0.628 & $0.437-0.464$ & 1.20 & 6.48 \\
\hline 0.5 & 0.797 & 0.582 & $0.432-0.398$ & 4.09 & 27.42 \\
\hline 1 & 0.841 & 0.540 & $0.427-0.350$ & 6.43 & 53.67 \\
\hline 2 & 0.884 & 0.488 & $0.416-0.301$ & 8.97 & 106.20 \\
\hline 3 & 0.898 & 0.458 & $0.406-0.277$ & 9.88 & 158.65 \\
\hline 4 & 0.901 & 0.438 & $0.399-0.265$ & 10.80 & 211.07 \\
\hline
\end{tabular}



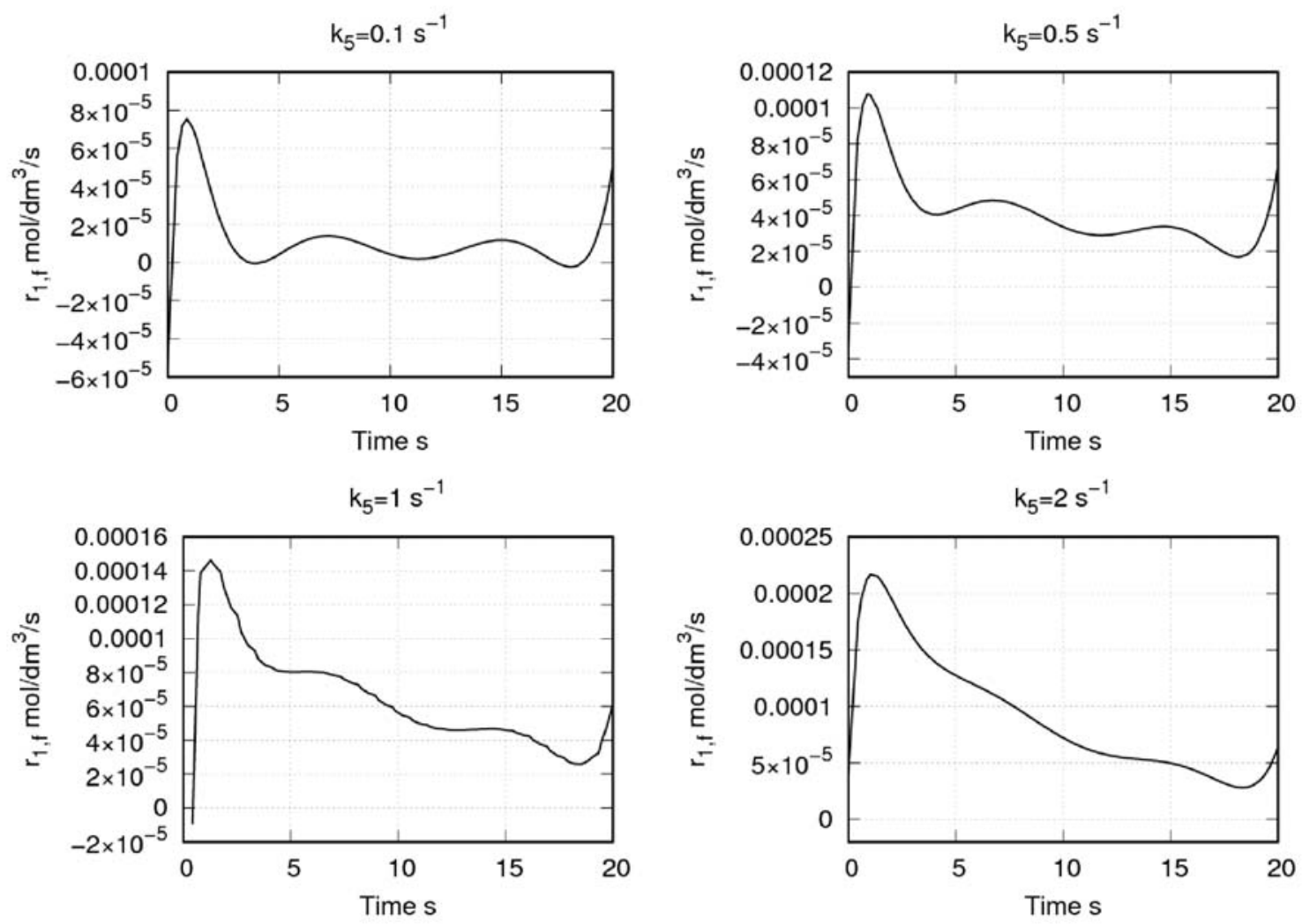

Figure 1. The component of the rate of change in the concentration of nitrogen monoxide $r_{1, \text { ef }}$ attributable to the reaction with nitrogen dioxide at different rates of removal of nitrogen trioxide from the gas phase

of approximate rate constants are collected in column 6 of Table 3 and column 3 of Table 5. These constants for low $\mathrm{k}_{5}$ values are only approximate, due to the undulating shape of curves reflecting the change in rate $r_{1, \text { ef }}$ (Fig.1).

The ratio of rate constants $\mathrm{k}_{1, \mathrm{e}} / \mathrm{k}_{-1, \mathrm{ef}}$ is equal to about 53 , regardless of $k_{5}$ constant value. At a temperature of $273 \mathrm{~K}$, the ratio of the rate constants of $\mathrm{k}_{1}$ and $\mathrm{k}_{-1}$ of the reaction (r1) is 53.26. Furthermore, the value of the constant $\mathrm{k}_{-1 \text {, ef }}$ is very close to the rate constant of the reaction ( $\mathrm{r} 5$ ), determining the amount of absorption.

In Fig. 2, the rate $r_{1, e f}$ was compared with the rate of concentration change $2 \mathrm{r}_{0}$, resulting from the reaction (r0) and with the total rate of nitrogen monoxide concentration change $-\mathrm{dc}_{\mathrm{NO}} / \mathrm{dt}$.

Formula (5) can be rewritten as:

$-d c_{N O} / d t=2 k_{0} c_{N O}^{2} c_{O_{2}}+k_{-1, e f} c_{N_{2} O_{3}}$

This is an accurate form of the expression for the rate of nitric oxide concentration loss in the system with the removal of nitrogen trioxide.

The expression above was compared with the equation in the form, in which the experimental rate of nitrogen monoxide oxidation with oxygen is described:

$$
-\frac{d c_{N O}}{d t}=A c_{N O}^{a} c_{O_{2}}^{b}
$$

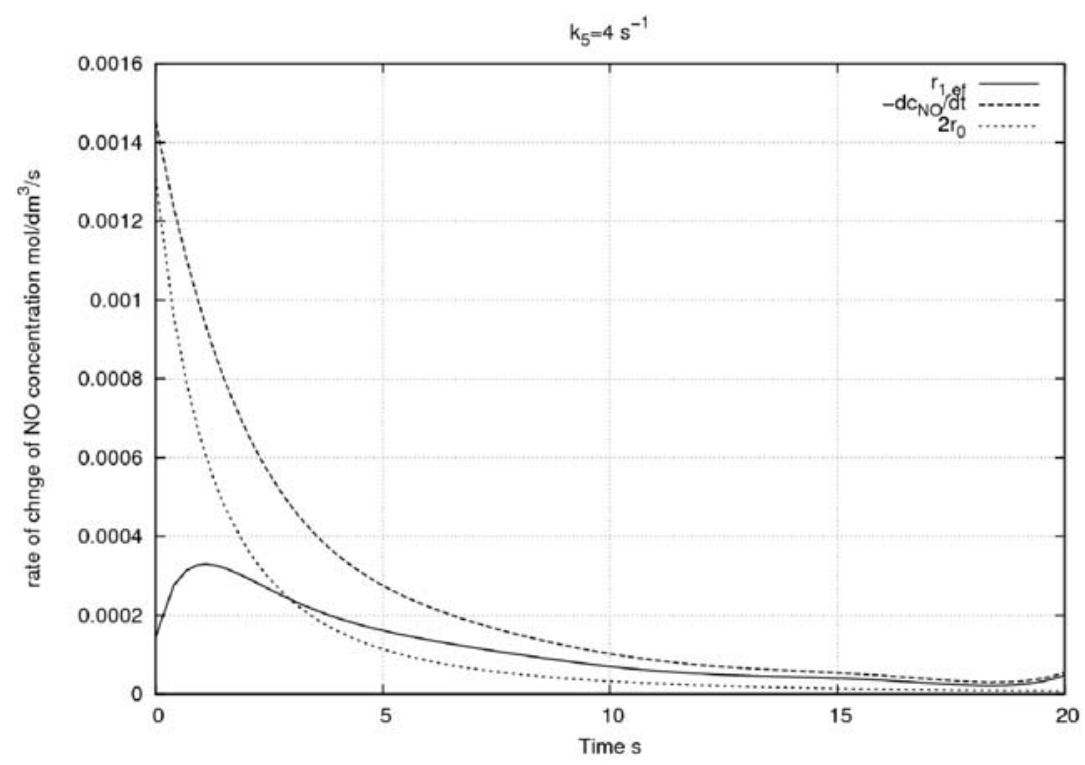

Figure 2. The rate of change of nitrogen monoxide concentration: total $-\mathrm{dc}_{\mathrm{NO} / \mathrm{dt}}$ and its components: $2 \mathrm{r}_{0}$ in reaction of nitrogen monoxide with oxygen and $r_{1, \text { ef }}$ - in reaction with nitrogen dioxide 
The accuracy of the description with the exponents $\mathrm{a}=2$ and $\mathrm{b}=1$ is relatively small and additionally deteriorates significantly as the constant $\mathrm{k}_{5}$ increases. Therefore, the variable values of exponents $a$ and $b$ were used. Since the concentration of nitrogen dioxide also appears in equation (7), the results were also compared with the equation, extended by the concentration of this oxide, i.e. equation ( $8 b)$ :

$-\frac{d c_{N O}}{d t}=B c_{N O}^{a} c_{O_{2}}^{b} c_{N O_{2}}^{c}$

The parameters of the formulas (8), collected in Table 4 , depending on the rate of nitrogen trioxide removal from the gas phase.

The mapping of the calculated rate of nitrogen monoxide concentration change by the formula ( $8 b)$ is more accurate. as a result of solving the set of differential equations (1). Moreover, it turns out, that the actual rates coincide with the rates of change in the „equilibrium” concentration of each of the mentioned nitrogen oxides.

The results collected in Table 1 (third column) and Table 2 clearly indicate the close relationship between the concentration of nitrogen oxides, imposed by both equilibrium reactions (r1) and (r2). The concentrations of nitrogen monoxide and nitrogen dioxide can be very accurately described by the equilibrium relations:

$$
\begin{aligned}
& c_{N O} \approx \frac{k_{-1} c_{N_{2} O_{3}}}{k_{1} c_{N O_{2}}} \\
& c_{N O_{2}} \approx\left(\frac{k_{-2} c_{N_{2} O_{4}}}{k_{2}}\right)^{1 / 2}
\end{aligned}
$$

Table 4. The rate of change in the concentration of nitrogen monoxide recorded with the equations of the power of nitrogen monoxide, oxygen and nitrogen dioxide

\begin{tabular}{|l|c|c|c|c|c|c|c|}
\hline $\mathrm{k}_{5}$ & \multicolumn{2}{|c|}{ Equation (8a) } & \multicolumn{3}{|c|}{ Equation (8b) } \\
& $\begin{array}{c}\mathrm{A} \\
\left(\mathrm{dm}^{3} / \mathrm{mol} / \mathrm{s}\right)^{\mathrm{a}+\mathrm{b}-1}\end{array}$ & $\mathrm{a}$ & $\mathrm{b}$ & $\begin{array}{c}\mathrm{B} \\
\left(\mathrm{dm}^{3} / \mathrm{mol} / \mathrm{s}\right)^{\mathrm{a}+\mathrm{b}+\mathrm{c}-1}\end{array}$ & $\mathrm{a}$ & $\mathrm{b}$ & $\mathrm{c}$ \\
\hline 0 & 124200 & 0.936 & 2.292 & 527000 & 0.735 & 2.700 & 0.0068 \\
\hline 0.1 & 41500 & 1.291 & 1.787 & 456100 & 0.651 & 2.749 & 0.0066 \\
\hline 0.5 & 7900.8 & 1.345 & 1.454 & 127100 & 0.832 & 2.367 & 0.0065 \\
\hline 1 & 2011.5 & 1.355 & 1.210 & 8880.5 & 1.210 & 1.578 & 0.0051 \\
\hline 2 & 184.1 & 1.471 & 0.693 & 1068.5 & 1.332 & 1.103 & 0.0046 \\
\hline 3 & 34.5 & 1.576 & 0.308 & 174.3 & 1.472 & 0.664 & 0.0041 \\
\hline 4 & 7.2 & 1.708 & -0.084 & 35.7 & 1.611 & 0.269 & 0.0004 \\
\hline
\end{tabular}

\section{DISCUSSION AND RESULTS}

The significant variability in the rates of the reaction ( $\mathrm{r} 0$ ) and the component reaction (r1) means, that the transformation of nitrogen monoxide to nitrogen trioxide, although inefficient, is most likely a continuous process. This suggestion may be supported by the following calculation-based observation: in the hypothetical absence of the $r_{-1}$ component of the nitrogen trioxide decomposition, slowing the nitrogen monoxide transformation the rate of nitrogen monoxide oxidation reaches only four times the value of $r_{0}$. The nitrogen dioxide formed in the reaction with oxygen is immediately converted to nitrogen trioxide. The nitrogen dioxide concentration then reaches the level of $1 \cdot 10^{-10}$, while its dimer concentration is only equal to $1 \cdot 10^{-19}(\mathrm{~mol} /$ $\mathrm{dm}^{3}$ ). This is a strong premise, that in a reacting system a continuous, immediate transformation of the nitrogen dioxide, formed in reaction $\left(\mathrm{r}_{0}\right)$ into nitrogen trioxide takes place. The decomposition of nitrogen trioxide is an equally fast reaction, which affects the inefficient contribution of the reaction $(\mathrm{r} 1)$ to the transformation of nitrogen monoxide.

The very rapid conversion of nitrogen dioxide to nitrogen trioxide allows the formation of a significant amount of $\mathrm{N}_{2} \mathrm{O}_{3}$ at the very beginning of the process. Its accumulation in the system is not affected by the decomposition of this oxide. The constant replenishment of this amount by the reaction (r0) allows maintaining the advantage of the rate of nitrogen trioxide decomposition over the rate of its formation.

The actual rate of change in concentration of nitrogen monoxide and nitrogen trioxide (dc/dt), as well as nitrogen dioxide and its dimer, is different from the rate obtained
The above dependencies, in connection with the results regarding the rate of nitrogen monoxide concentration change, confirm the close relationship between the nitrogen monoxide oxidation and the very fast reaction of nitrogen trioxide formation (and decomposition). The removal of nitrogen trioxide from the gas phase disturbs the equilibrium of the reaction ( 11$)$ and promotes the formation of nitrogen trioxide in the reaction of $\mathrm{NO}$ with $\mathrm{NO}_{2}$. If nitrogen trioxide(III) does not leave the gas phase, the reaction of nitrogen monoxide oxidation by oxygen runs only to the extent, that it itself disturbs the equilibrium of the reaction (r1).

The interaction of the reactions (r0) and (r1), suggests the desirability of describing the rate of nitrogen monoxide oxidation by oxygen, with an expression containing a combination of the concentrations of components, present in the reacting system. One of these expressions has the form:

$r_{0}=k_{0}\left(\frac{k_{-1}}{k_{1}}\right)^{2} \frac{k_{2}}{k_{-2}} c_{O_{2}} \frac{c_{N_{2} O_{3}}^{2}}{c_{N_{2} O_{4}}}$.

The substitute rate constant $\mathrm{k}$ of the equation for the rate of nitrogen monoxide oxidation is now given by the typical Arrhenius dependence:

$k=6.24 \cdot 10^{7}(T / 298)^{-2} \exp (-2770 / T) ; d m^{3}(m o l s)^{-1}$

The numerical value of the substitute constant, estimated from the simulation results does not depend on whether the nitrogen trioxide leaves the reacting system or not.

If the nitrogen trioxide is removed from the system, it is convenient to write the equation (7) in the form (7a): 
$-\frac{d c_{N O}}{d t}=2 r_{0}(1+\gamma)$

where $r_{0}$ is now given by the equation (10a) while $\gamma$ is the ratio of the oxidation rate of nitrogen monoxide with nitrogen dioxide and oxygen, equal to $\gamma=\frac{k_{-1, e f} c_{N_{2} O_{3}}}{2 r_{0}}$. In equation (7a), the following rate constants were used: $k$ - from the equation (10b) and constant $\mathrm{k}_{-1, \mathrm{ef}}$ which was determined from the linear regression equation, reflecting the actual rate of nitric oxide concentration change. The numerical values of the above constants are associated with the rate constant $\mathrm{k}_{5}$ and the parameter $\gamma$ (table 5).

Table 5. Comparison of the share of $\gamma$ of the nitrogen oxide (oxidation reaction with nitrogen dioxide as compared to the share (equal to 1 ) of the oxidation of nitrogen monoxide with oxygen. The value of parameter $\mathrm{k}$ is $2915.25 \mathrm{dm}^{3} / \mathrm{mol} / \mathrm{s}$

\begin{tabular}{|c|c|c|}
\hline $\begin{array}{c}\text { Rate constant } \mathrm{k}_{5} \\
\mathrm{~s}^{-1}\end{array}$ & $\begin{array}{c}\text { Rate constant } \mathrm{k}_{-1, \text { ef }} \\
\mathrm{s}^{-1}\end{array}$ & $\begin{array}{c}\text { Parameter } \mathrm{y} \\
\text { (final value) }\end{array}$ \\
\hline 0 & 0.022 & 0.051 \\
\hline 0.1 & 0.119 & 0.275 \\
\hline 0.5 & 0.511 & 1.146 \\
\hline 1 & 1.003 & 2.126 \\
\hline 2 & 1.990 & 3.443 \\
\hline 3 & 2.973 & 3.646 \\
\hline 4 & 3.952 & 3.087 \\
\hline
\end{tabular}

The value of $\gamma$ increases practically linearly during the NO transformation to the value given in Table 5 for small and moderately large $\mathrm{k}_{5}$ values. For $\mathrm{k}_{5}$ equal to 3 and 4 , the change of this parameter takes place along the concave curve. In the final stage of nitrogen monoxide oxidation, the reaction rate (r1) significantly exceeds the reaction rate $(\mathrm{r} 0)$. As a result, the degree of nitrogen monoxide conversion increases.

\section{CONCLUSION}

Simulations of the transformation of nitrogen monoxide to nitrogen dioxide were performed in the systems without and with the removal of nitrogen trioxide. The monitored variables included the nitrogen monoxide conversion degree $\alpha$, the oxygen conversion degree $\beta$ and the rates of concentration changes for all the components of the mixture reacting in the gaseous phase. The oxidation reaction $(\mathrm{r} 0)$ of nitrogen monoxide with oxygen was analysed in detail.

Reaction (r0) is accompanied by two very fast reactions: (r1), in which nitrogen trioxide is formed, and (r2), in which nitrogen tetra-oxide is formed. The equilibrium of the fast reactions imposes significant limitations on the effective transformation of nitrogen monoxide in the slow reaction $(\mathrm{r} 0)$. It may be stated that this reaction becomes involved in an equilibrium behaviour. The concentrations of the substrate and product of the slow reaction achieve the equilibrium values determined by the reactions ( $\mathrm{r} 1)$ and ( $\mathrm{r} 2)$.

The slow course of the reaction ( $\mathrm{r} 0)$ permanently disturbs the equilibrium of reactions (r1) and (r2) and at the same time is strongly limited by these equilibria - especially that of reaction (r1). In the system without removal of $\mathrm{N}_{2} \mathrm{O}_{3}$, this results in a slow conversion of nitrogen monoxide. Removal of di-nitrogen oxides, in particular nitrogen trioxide, facilitates the conversion of nitrogen monoxide. The contribution of reaction ( $\mathrm{r} 1)$ to the conversion of nitrogen monoxide was estimated.

The results of the interrelationship of the three analysed reactions are the equilibrium relationships (9a) and $(9 b)$, determining the concentrations of nitrogen monoxide and nitrogen dioxide. These relationships, introduced into the classical kinetic equation on the rate of the slow reaction ( $\mathrm{r} 0$ ) of nitrogen monoxide oxidation with oxygen, lead to the equation (10a). The kinetic constant shows a temperature dependence typical for a chemical reaction.

\section{NOTATION}

A - constant parameter in equation $(8 \mathrm{a}),\left(\mathrm{dm}^{3} /\right.$ $\mathrm{mol} / \mathrm{s})^{\mathrm{a}+\mathrm{b}-1}$

B - constant parameter in equation $(8 \mathrm{~b}),\left(\mathrm{dm}^{3} /\right.$ $\mathrm{mol} / \mathrm{s})^{\mathrm{a}+\mathrm{b}+\mathrm{c}-1}$

$\mathrm{a}, \mathrm{b}, \mathrm{c}-$ constant parameters in equations $(8 \mathrm{a})$ and $(8 \mathrm{~b})$

$\mathrm{c}_{\mathrm{i}}-$ concentration of the $\mathrm{i}$-th component, $\mathrm{mol} / \mathrm{dm}^{3}$

$\mathrm{dc}_{\mathrm{i}} / \mathrm{dt}$ - the actual rate of concentration change, $\mathrm{mol} /$ $\left(\mathrm{dm}^{3} \mathrm{~s}\right)$

$\mathrm{k} \quad$ - rate constant: $\mathrm{k}_{\mathrm{j}}$ and $\mathrm{k}_{-\mathrm{j}}$ of the $\mathrm{j}$-th reaction

$r_{j} \quad-$ rate of reaction $(\mathrm{rj}), \mathrm{mol} /\left(\mathrm{dm}^{3} \mathrm{~s}\right), \mathrm{j}=0,1, \ldots 4,5$

$\mathrm{r}_{\mathrm{i}} \quad$ - rate of concentration change, $\mathrm{mol} /\left(\mathrm{dm}^{3} \mathrm{~s}\right)$; simulated quantity

$r_{1, \text { ef }}$ and $r_{-1, \text { ef }}-$ components of the reaction rates $(\mathrm{r} 1)$ contributing to the NO conversion

t - time, s

$\alpha \quad$ - conversion degree of NO

$\beta-$ conversion degree of $\mathrm{O}_{2}$

$\gamma \quad$ - parameter determined by the equation (7a)

$\Delta \mathrm{r} \quad$ - rate described by the formula (5)

\section{ACKNOWLEDGMENT}

The work was supported by the Ministry of Science and Higher Education of Poland within a frame of statutory activity grant realized in Faculty of Chemistry, Wroclaw University of Science and Technology (No. 0401/0199/17W3/Z14, 2017-2018) .

\section{LITERATURE CITED}

1. Atkins, P.W. (1990). Phys.Chem., Oxford Univ. Press, Oxford

2. Pigoń, K. \& Ruziewicz, Z. (1986). Phys. Chem., PWN, Warsaw, (in Polish).

3. Olbregts, J. (1985). Thermolecular reaction of nitrogen monoxide with oxygen; A still unsolved problem, Inter. J. Chem. Kinet., 17, 835-845.

4. Patwardhan, J.A. \& Joshi, J.B. (2003). Unified model for $\mathrm{NO}_{\mathrm{x}}$ absorption in aqueous alkaline and dilute acidic solutions, AIChE J. 49(11), 2728-2748. DOI: 10.1002/aic.690491106.

5. NIST Chemical Kinetics Database, User's Guide (https:// kinetics.nist.gov/).

6. POLYMATH 6.1 Professional Use Version (http://www. polymath software.com/).

7. Głowiński, J., Hałat, A., Biskupski, A., Kędzior, R. \& Nieweś, D. (2018). Role of nitrogen trioxide in the oxidation of nitric oxide with oxygen, Chem. Industry, 97(9), 1000-1004. (in Polish). 